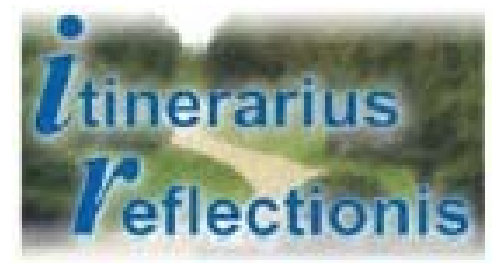

Revista Eletrônica de Educação do Curso de Pedagogia do Campus Jataí da Universidade Federal de Goiás

[Vol I - n.4 ] [jan/jul] [ 2008]

\title{
REFLEXÕES SOBRE ESCOLA E INCLUSÃO
}

FRANCO, Érika Maridelma de Lima Santos. Graduada em Pedagogia pelo Campus Jataí /UFG. SOUSA NETO, Alípio Rodrigues de. Mestre em Educação Brasileira, professor do Curso de Pedagogia do Campus - Jataí/UFG.

RESUMO: No transcorrer das últimas décadas do século passado, diversos movimentos sociais organizam-se trazendo à tona a discussão sobre as necessidades fundamentais do homem. As lutas destes movimentos sociais consubstanciaram-se nos direitos da criança e do adolescente, dos índios, das mulheres, dos negros, dos homossexuais, dos portadores de necessidades especiais, na luta pela preservação da natureza, contra a violência e por um mundo menos desigual. Nesse cenário histórico, emerge a luta pela inclusão de segmentos significativos da população no campo político, econômico, cultural e educacional. No campo educacional, a inclusão tem sido vista de maneira equivocada, o que tem levado os educadores a pensarem a inclusão somente das pessoas com deficiências físicas. A inclusão busca se opor a exclusão, privilegiando a igualdade dentro da instituição escolar, dando ênfase a uma educação que busque garantir a aprendizagem das pessoas que necessitam da mesma. A escola, para fazer frente às diferenças de cada aluno, deve reorganizar o trabalho pedagógico, trabalhando as diferentes formas de aprender e ensinar dentro de uma única sala de aula.

\section{Palavras-chave: educação inclusiva; diversidade sócio-cultural.}

ABSTARCT: Throughout the last decades in the last century, diverse social movements have been organized bringing the discussion on the fundamental needs of the man. The struggle of such social movements concretized in the rights of the children and teenagers, of the indians, of the women, of the black people, of the homossexuals, of the disabled people, in the fight for the nature preservation, against the violence and in favor of a less unfair world. In this historical context, the inclusion opposes to the exclusion highlighting the equality in the school, focusing on an education that seeks to guarantee the learning of people who need it. The school, in face of each learners' difference, has to reorganize the pedagogical work, dealing with the different forms of learning and teaching within a single classroom.

key-words: inclusive education; socio-cultural diversity. 


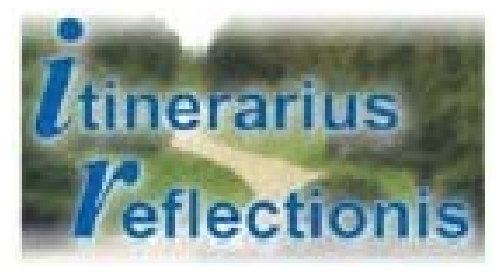

Revista Eletrônica de Educação do Curso de Pedagogia
do Campus Jataí da Universidade Federal de Goiás
[Vol I - n.4 ] [jan/jul] [ 2008]
ISSN: 1807-9342

No transcorrer, principalmente das duas últimas décadas do século passado, diversos movimentos sociais organizam-se trazendo à tona a discussão sobre a busca da satisfação de necessidades fundamentais do homem, necessidades de caráter social, cultural, político e econômico. As lutas destes movimentos sociais consubstanciaram-se nos direitos da criança e do adolescente, dos índios, das mulheres, dos negros, dos homossexuais, dos portadores de necessidades especiais, na luta pela preservação da natureza, contra a violência e por um mundo menos desigual. De acordo com BARRETO:

\footnotetext{
Os novos atores em cena buscam colocar seus interesses específicos não mais como circunscritos a um âmbito restrito de reivindicações, mas afetando o conjunto dos indivíduos da sociedade, à medida que demanda a mudança de todo o padrão de relações sociais que nela se estabelece. E o fazem recusando a busca de consensos homogeinizadores [...] e restaurando a dinâmica do conflito que passa por uma linguagem política particularista, a qual reclama por autonomia e coloca entre parênteses a totalidade com vistas a anular toda a hierarquia entre as diferenças. (1998.p.19).
}

Nesse cenário histórico, emerge a luta pela inclusão de segmentos significativos da população no campo político, econômico, cultural e educacional, como expressão de interesses de grupos classificados socialmente como "minoritários", o que expressa a necessidade de uma participação mais ativa no processo de reestruturação das relações sociais, visando construir uma sociedade mais justa, democrática, plural, onde as diferenças possam se expressar como direito à cidadania.

No transcorrer da década de 1990, organizaram-se diversas conferências internacionais das quais resultaram documentos importantes para o pensar/repensar uma educação inclusiva. Pela relevância que assumiu na orientação de políticas públicas em diversos países, destacamos a Declaração Mundial de Educação para Todos, de 1990.

O Documento estabelece objetivos que tem como horizonte uma educação destinada a todos os cidadãos, independente de raça, gênero, idade, das habilidades físicas e cognitivas de cada pessoa. Assim, todos devem ter acesso à escolaridade, aos bens culturais construídos 


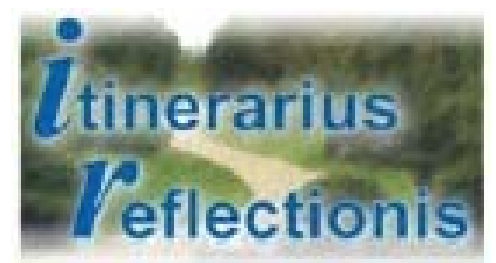

\section{Revista Eletrônica de Educação do Curso de Pedagogia do Campus Jataí da Universidade Federal de Goiás \\ [Vol I - n.4 ] [jan/jul] [ 2008] \\ ISSN: $1807-9342$}

socialmente, ao processo de produção e de difusão do conhecimento, utilizando-o para o exercício de sua cidadania. (CARVALHO, 2005)

Com relação às pessoas com necessidades especiais, o artigo $3^{\circ}$ da Declaração

Mundial estabelece o seguinte objetivo:

Universalizar o acesso à educação e promover a equidade [...] cinco. As necessidades básicas de aprendizagem das pessoas portadoras de deficiências requerem atenção especial. É preciso tomar medidas que garantam a igualdade de acesso à educação aos portadores de todo e qualquer tipo de deficiência, como parte integrante do sistema educativo.

Ainda, o referido Documento destaca que os governos dos diversos países devem ter:

Programas desenhados para satisfazer as necessidades básicas de aprendizagem de grupos desassistidos, jovens fora da escola e adultos com pouco ou nenhum acesso à educação básica. Todos os parceiros poderão compartilhar suas experiências e competências na concepção e execução de medidas e atividades inovadoras, bem como concentrar seus financiamentos para a educação básica em categorias e grupos específicos (por exemplo: mulheres, camponeses pobres, portadores de deficiências), e assim melhorar significativamente as oportunidades e condições de aprendizagem que lhes são acessíveis.

No Brasil, essa discussão assume contornos mais definidos, com a Lei n. 9.394/1996

(LDBEN) que, trata no Artigo 58, 59 e 60 da Educação Especial no país. Segundo SOUSA e SILVA (1997):

A Lei 5.692 dedicou apenas um artigo ao tema (artigo $9^{\circ}$ ) o que, à época, foi muito criticado pelos especialistas da área. Todavia, a partir dele, muitas normas foram editadas, muitas experiências foram desenvolvidas pelos sistemas de ensino. Assim, o que é novo e auspicioso, é a inserção nesta LDB, de temas antes só tratados em Decretos, Portarias ou normas, nos diversos sistemas de ensino (...). (p. 95) 


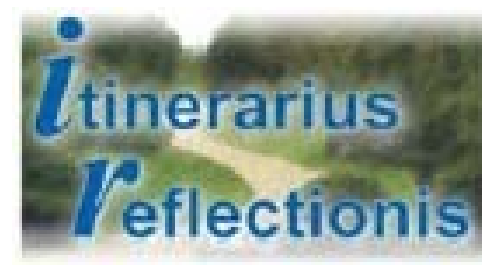

Revista Eletrônica de Educação do Curso de Pedagogia do Campus Jataí da Universidade Federal de Goiás

[Vol I - n.4 ] [jan/jul] [ 2008]

ISSN: 1807-9342

Assim sendo, houve um significativo avanço com relação à Legislação anterior, já que a atual LDBEN trás todo um capítulo dedicado a educação especial. No Artigo 58 a Lei de 1996 nos diz o seguinte:

Entende-se por educação especial, para efeitos desta Lei, a modalidade de educação escolar, oferecida preferencialmente na rede regular de ensino, para educandos com necessidades especiais.

$\S 1^{\circ}$ - Haverá, quando necessário, serviços de apoio especializado, na escola regular, para atender às peculiaridades da clientela de educação especial.

$\S 2^{\circ}-\mathrm{O}$ atendimento educacional será feito em classes, escolas ou serviços especializados, sempre que, em função das condições específicas dos alunos, não for possível a sua integração nas classes comuns de ensino regular.

$\S 3^{\circ}$ - A oferta de educação especial, dever constitucional do Estado, tem início na faixa etária de zero a seis anos, durante a educação infantil.

Pelo que podemos entender do Artigo 58 e seus respectivos parágrafos, além de haver a identificação do que seja educação especial, estabelece que o atendimento a essa população seja realizado preferencialmente nas escolas da rede regular de ensino. Somente como exceção, o aluno especial será encaminhado para classes, escolas ou serviços especializados.

A Lei de 1996 incorpora os temas IGUALDADE e DIFERENÇA, voltando-se para a defesa de uma educação que assuma a diversidade como princípio e que possa atender na rede regular de ensino alunos que apresentem necessidades educacionais especiais.

No entanto, a educação inclusiva ainda não é encarada como algo necessário e urgente na maioria das escolas brasileiras. Ainda hoje tem sido interpretada de maneira equivocada, pois muitos educadores ainda a vêem como uma simples assistência aos deficientes físicos e não como uma educação de alunos que apresentam necessidades educacionais especiais. Nesse sentido, merece destaque o que nos afirma CAVALCANTE: "a educação especial não é apenas cumprir a lei, mais do que isso, deve ser entendida como uma modalidade de ensino que tem como objetivo quebrar as barreiras que impedem a criança de exercer sua cidadania.” (2005; p.43 e 45)

Nestes termos, é tarefa do professor, enquanto educador que se preocupa com a igualdade, formar seres humanos equilibrados independentemente de possíveis imperfeições físicas, mentais ou emocionais. Assim, toda criança tem condições para aprender desde que 
devidamente estimulada, pois possui capacidades de arregimentar forças inimagináveis que o fará irem além dos obstáculos da vida. Cada indivíduo possui características específicas e é de suma importância que o educador que se preocupa tanto com a cognição quanto com o social, acredite na capacidade de aprendizagem dos alunos, fator fundamental para impulsionar o processo de ensinar-aprender, levando em conta a diversidade e procurando sempre saber quem é o aluno e como ele aprende.

É importante também salientar que, para que uma escola se torne inclusiva não se deve esperar que os alunos que apresentam necessidades educacionais especiais se adaptem a esta, mas que a escola se transforme de forma a possibilitar a inclusão dessa criança na instituição escolar. Nesse sentido, MANTOAN afirma que: "uma sociedade justa, que dê oportunidades para todos, sem qualquer tipo de discriminação, começa na escola.” (2005; p. 24).

Assim, a escola não deve somente fazer adaptações físicas, mas precisa oferecer atendimento educacional especializado, de modo que estas crianças se adaptem e aprendam a conviver com a diferença e se tornem cidadãos solidários e que compreendam a escola bem como a sociedade como um espaço da diversidade. A inclusão emerge em nossa sociedade como uma nova modalidade que não apenas tem o enfoque na defesa da cidadania e do direito à educação das pessoas que necessitem de educação especial, como também traz uma perspectiva voltada às concepções de educação, como o ensinar e o aprender que envolve não só o aluno especial, como também o professor que será levado a questionar e buscar conhecimentos para lidar com esse desafio que lhe é proposto.

Com isso, o professor precisa abandonar a idéia de que não teve preparação para lidar com esses alunos. É enfrentando a situação do dia-a-dia e buscando meios para compreender o sentido da educação especial que o professor vai adquirindo saberes, desenvolvendo suas potencialidades e habilidades necessárias para atender os alunos com necessidades especiais. Conforme MANTOAN (2005), não existe método de ensino especial para se ensinar os conteúdos curriculares para os alunos com necessidades educacionais especiais. Portanto, o que o professor necessita é se preparar para atender todas as crianças, levando em consideração que 


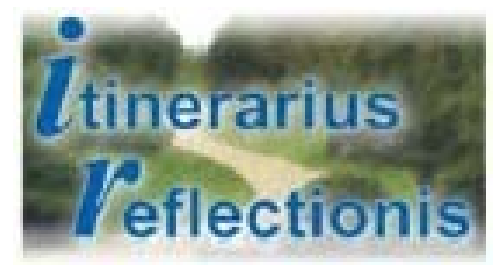

Revista Eletrônica de Educação do Curso de Pedagogia do Campus Jataí da Universidade Federal de Goiás

[Vol I - n.4 ] [jan/jul] [ 2008]

cada criança tem uma maneira diferenciada para aprender, pois há diversas maneiras de promover o aprendizado, tendo essa criança uma necessidade especial ou não.

Tais preparações que devem ser adquiridas pelo professor estão interligadas a sua própria experiência do dia-a-dia. A formação se faz vivendo, na prática, na interação, no exercício do trabalho. Assim, conforme TARDIF (2002), a aprendizagem da docência ocorre também com a prática cotidiana, na qual o docente vai construindo saberes experienciais. Os professores desenvolvem saberes específicos baseados no seu trabalho cotidiano e no conhecimento de seu meio.

Nesse processo, há uma relação entre políticas e práticas. Assim, uma política pública é formulada e posta em prática para que se atenda a todos, de modo que se priorize a diversidade, tendo como meta combater a discriminação, dando assim maior ênfase ao direito de igualdade e oportunidade. É nesse contexto que BRANDÃO enfatiza que a discriminação vem sendo vivenciada desde a abolição da escravatura e "o fruto dessa herança discriminatória e desigual é manifestação de um Brasil branco e de um Brasil negro, mesmo após 116 anos da abolição da escravatura". (2003).

Assim, percebemos a desigualdade como fruto de uma historia comum entre milhões de brasileiros. O segmento das pessoas portadoras de necessidades especiais não deixa de ser fruto também dessa manifestação discriminatória, na qual deixou marcas que nos aflige mesmo depois de dezenas de anos.

Em contra partida, a inclusão não deve ser encarada como apenas um atendimento direcionado as pessoas com deficiência, mas abrange grande parte da população como negros, índios, a classe pobre e mesmo migrante.

Vivemos um cenário de profundas transformações no campo econômico, social, político e cultural em função do processo de globalização e do avanço tecnológico, o que tem permitido a ampliação da rede de comunicação e de transporte. Vivenciamos um momento de reestruturação da produção de mercadorias, de reorganização do trabalho, de crise de emprego. Desta forma, a globalização econômica, o avanço tecnológico, o aperfeiçoamento dos meios de 


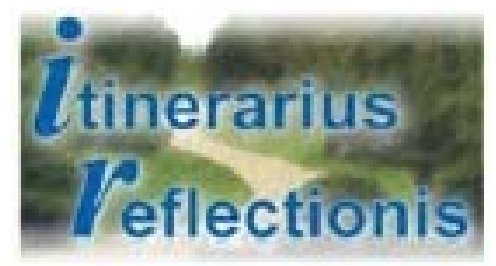

Revista Eletrônica de Educação do Curso de Pedagogia do Campus Jataí da Universidade Federal de Goiás

[Vol I - n.4 ] [jan/jul] [ 2008]

comunicação e de transporte, as mudanças tecnológicas, etc., não tem proporcionado uma melhoria na qualidade de vida da população mundial de uma forma geral ou, de forma mais específica, no Brasil. Segundo TIBALLI:

as leis da livre concorrência e competitividade gerariam o equilíbrio social, e, através do avanço técnico cientifico em beneficio das pessoas, atingir-se-ia uma idade de ouro, de progresso e bem-estar. Em vez de uma idade de ouro, o que temos hoje, no Brasil? Uma serie de problemas: violência corrupção, aviltamento do ser humano, prostituição, uma sociedade de desiguais e excluídos, índios e mendigos sendo queimados. (2003; p.210)

Nesse contexto, resta-nos buscar responder a seguinte questão: será que o avanço tecnológico realmente gera melhorias na qualidade de vida das pessoas em todos e em qualquer sentido? É importante salientar que os problemas gerados pela globalização são fruto do fortalecimento da dominação econômica e da primazia do individual, do particular, o que faz perder o valor do social, o valor do coletivo humano.

Nesse sentido, enquanto assistimos a um movimento de ampliação de oportunidades educacionais, econômicas e culturais, as transformações que vivenciamos reproduz uma sociedade desigual. A escola, que faz parte deste contexto histórico/social, acaba por refletir de alguma forma a discriminação contribuindo para aumentar a exclusão social.

Em razão disso, a inclusão tem sido vista de maneira equivocada o que leva os educadores a pensarem somente nos deficientes físicos. Portanto, a inclusão é mais do que isso. Ela busca se opor a exclusão, privilegiando a igualdade dentro da instituição escolar, dando ênfase a uma educação que busque garantir a aprendizagem de milhares de pessoas que necessitam da mesma. Toda escola que se pretenda inclusiva deve adotar princípios que norteiem as ações produzidas e reproduzidas no seu chão visando o acesso de todos os alunos a uma educação de qualidade. 
É interessante o que nos afirma TIBALLI quando diz: "Tenho a conviç̧ão de que toda pessoa capaz de interagir de algum modo com outra pessoa é também capaz de aprender". (2003; p. 195)

Assim, compreendemos que a aprendizagem acontece de acordo com a vivência e experiência do dia-a-dia, à medida que há a interação de uma criança com outras crianças. Nesse aspecto, encontramos nas palavras de FORQUIN uma importante argumentação que reitera a necessidade de repensarmos as relações construídas no espaço escolar e que acabam por marginalizar parte das crianças que freqüentam as salas de aula: "Não há culturalmente deficientes em si; o que existe são grupos desfavorecidos em face da escola. E é a própria escola que é, em grande parte, responsável pelo fracasso escolar das crianças...”. (1993; p.47)

Considerando essas palavras, para que a escola possa fazer frente às diferenças de cada aluno e atenda a todos, dando oportunidades para que todas as crianças tenham acesso ao aprendizado é relevante ao seu funcionamento, que a mesma tenha materiais adequados e suficientes ao seu uso e ofereça aos seus professores a qualificação profissional adequada para atender a diversidade e trabalhar as diferentes formas de aprender e ensinar dentro de uma única sala de aula. Contudo, não é a criança que deve se adaptar a escola, mas a escola é que deve se adaptar ao processo ensinar-aprender e atender a diversidade social, lutando pela construção de uma sociedade que respeite as diferenças e as especificidades de cada cidadão, de maneira que atenda a todos de forma justa e eficaz, permitindo que cada criança tenha o direito a um bom ensino e que possa ser formada como cidadãos críticos e capazes de exercer sua autonomia.

A partir dessa perspectiva, a escola como uma instituição que atenda a diversidade e que ofereça oportunidades de uma boa qualidade de ensino deve respeitar não só as diferenças que traz cada um de seus alunos, mas deve também respeitar a cultura e principalmente o ritmo próprio de aprendizagem que cada aluno traz consigo na sua maneira própria de viver. 


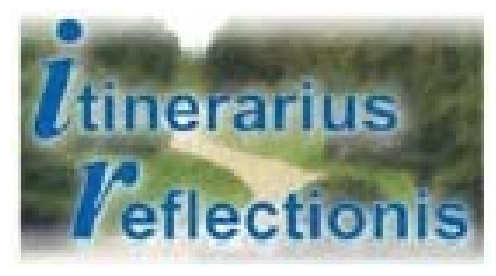

Revista Eletrônica de Educação do Curso de Pedagogia do Campus Jataí da Universidade Federal de Goiás

[Vol I - n.4 ] [jan/jul] [ 2008]

\section{BIBLIOGRAFIA}

BARRETO, Elba Siqueira de Sá (Org.). Os Currículos do Ensino Fundamental para as escolas Brasileiras. Campinas: Autores Associados, 1998.

BRANDÃO, A.A.Raça, Demografia e Indicadores Sociais. In: OLIVEIRA, I.de. (Org.) Relações raciais e educação: novos desafios. Rio de Janeiro: dp \& a, 2003.

CAVALCANTE, Meire. A escola que é de todas as crianças. NOVA ESCOLA, São Paulo, p.40 a 45, maio, 2005.

FORQUIN, J.C. Escola e cultura. As bases sociais e sociais e epistemológicas do conhecimento escolar. Porto Alegre: Artes Medicas, 1993.

MANTOAN, Maria Tereza Égler. A Inclusão e o privilégio de conviver com as diferenças. NOVA ESCOLA, São Paulo, p.24 a 26, maio, 2005.

MAZZOTTA, Marcos José Silveira. Educação Especial no Brasil: Historia e Política Publica. $5^{\mathrm{a}}$ ed. São Paulo: Cortez, 2005.

TARDIF, M. Saberes docentes e formação profissional. Petrópolis vozes, 2002.

TIBALLI, Eliandra F.Arantes. Estratégias de inclusão frente a diversidade social e cultural na escola. In: LISITA, Verbena Moreira S. de S.; SOUZA, Luciana Freire E. C. P. (ORG.).Políticas educacionais, praticas escolares e alternativas de inclusão escolar. Rio de Janeiro: DP \& A, p. 195-208, 2003. 